\title{
Analisis Hubungan Faktor Sosial Ekonomi Petani Terhadap Pengetahuan Budidaya Pertanian Organik Padi Sawah (Oryza sativa L.) di Kelurahan Makroman Kecamatan Sambutan
}

\author{
Eko Setiawan Prabowo ${ }^{1}$, Tetty Wijayanti ${ }^{2}$, dan Saddaruddin ${ }^{3}$ \\ 1,2,3 Program Studi Agribisnis Faperta Universitas Mulawarman Samarinda \\ 2Email: tettywijayanti_akbar@yahoo.com
}

\begin{abstract}
The level of knowledge of farmers on the cultivation of organic lowland rice farming was influenced by socio-economic factors. The purpose of this research was to know the role of social economic factors farmers to knowledge of organic lowland rice farming cultivation, knowing the level of knowledge of farmers on the cultivation of organic lowland rice farming and knowing whether there was a relationship between socioeconomic factors to knowledge of organic lowland rice farming cultivation in the Village of Makroman, Sub Districts of Sambutan. This research was carried out for three months from April to June 2017. Location was determined purposively in the Village of Makroman, Sub Districts of Sambutan. The determination of respondents was done by Proportionate Random Sampling method with the number of respondents is 38 people. Socio-economic factors of farmers to the knowledge of organic lowland rice farming cultivation was measured using Likert scale. Test to determine the relationship between socio-economic factors of farmers on knowledge of organic lowland rice farming cultivation used spearman rank analysis. The results showed that socio-economic factors of farmers to the knowledge of organic lowland rice farming cultivation in the less category with the average score of 56.28 and the level of knowledge of farmers on the cultivation of organic farming of rice in the high category with an average score of 60.10 . With a significant test of spearman rank shows that the correlation of socio-economic factors of farmers to the cultivation of organic farming of rice was significant with the value of 0.892. Significant test results show the value of $t$ arithmetic 11,819 >t tabel 0,219 . Socio-economic factors of farmers on the cultivation of organic farming of lowland rice in the category of less role. Level of knowledge of farmers on the cultivation of organic agriculture of lowland rice in high category. There was a relationship between socio-economic factors of farmers on the cultivation of organic rice farming.
\end{abstract}

Keywords: Social-Economy, Knowledge, Organic Lowland Rice

\begin{abstract}
ABSTRAK
Tingkat pengetahuan petani terhadap budidaya pertanian organik padi sawah dipengaruhi oleh faktor sosial ekonomi. Tujuan dari penelitian ini adalah mengetahui peran faktor sosial ekonomi petani terhadap pengetahuan budidaya pertanian organik padi sawah, mengetahui tingkat pengetahuan petani terhadap budidaya pertanian organik dan mengetahui apakah terdapat hubungan antara faktor sosial ekonomi petani terhadap pengetahuan budidaya pertanian organik padi sawah di Kelurahan Makroman Kecamatan Sambutan. Pengambilan sample menggunakan metode Proportionate Random Sampling dengan jumlah responden sebanyak 38 jiwa. Hasil penelitian menunjukkan bahwa faktor sosial ekonomi petani terhadap budidaya pertanian organik padi sawah dalam kategori kurang berperan dengan skor rata-rata 56,28 dan tingkat pengetahuan petani terhadap budidaya pertanian organik padi sawah dalam kategori tinggi dengan skor rata-rata 60,10. Dengan uji signifikan rank spearman menunjukkan bahwa hubungan antara faktor sosial ekonomi petani terhadap budidaya pertanian organik padi sawah adalah signifikan dengan nilai 0,892 . Hasil uji signifikan menunjukkan nilai t hitung 11,819 > t tabel 0,219. Faktor sosial ekonomi petani terhadap budidaya pertanian organik padi sawah dalam kategori kurang berperan. Tingkat pengetahuan petani terhadap budidaya pertanian organik padi sawah dalam kategori
\end{abstract}


tinggi. Terdapat hubungan antara faktor sosial ekonomi petani terhadap budidaya pertanian organik padi sawah.

Kata kunci : Sosial Ekonomi, Pengetahuan, Padi Organik

\section{Pendahuluan}

Memasuki abad 21, gaya hidup sehat dengan slogan Back To Nature telah menjadi tren baru masyarakat. Masyarakat semakin menyadari bahwa penggunaan bahan kimia anorganik seperti: pupuk anorganik, pestisida anorganik, dan hormon tumbuh dalam produksi pertanian berdampak negatif terhadap kesehatan manusia dan lingkungan. Akibat dari dampak negatif bahan kimia anorganik masyarakat semakin selektif dalam memilih pangan yang aman bagi kesehatan dan ramah lingkungan. Pangan yang sehat dapat diproduksi dengan teknologi pertanian organik (Amaliah, 2014).

Pertanian organik merupakan pertanian masa depan untuk menciptakan pangan yang sehat dan aman dengan pendekatan biologis, mekanis, dan fisik dengan meminimalkan penggunaan bahan kimia anorganik sejak dari produksi sampai siap konsumsi. Pertanian organik muncul akibat berkurangnya kesuburan tanah dan kerusakan lingkungan akibat pemakaian pupuk dan pestisida kimia yang tidak terkendali, sehingga dengan adanya pertanian organik dapat mengembalikan kesuburan tanah dan memperbaiki kerusakan lingkungan dari dampak pertanian anorganik (Susanti, 2008).

Petani menjadi salah satu pelopor yang dapat mengembangkan budidaya pertanian organik karena petani merupakan pelaku dalam kegiatan berusahatani, tetapi terbatasnya pengetahuan petani tentang budidaya pertanian organik menjadi salah satu kendala yang dihadapi. Pengetahuan petani terhadap pertanian organik masih terbatas pada jenis pupuk organik dan pestisida organik yang digunakan, sedangkan pada budidaya pertanian organik tidak hanya pupuk dan pestisida organik saja yang digunakan, tetapi penggunaan benih varietas unggul, pengendalian hama dan penyakit terpadu, konversi lahan pertanian konvensional menjadi lahan pertanian organik, dan irigasi pertaian organik yang terpisah dari irigasi pertanian konvensional juga menjadi faktor yang mempengaruhi budidaya pertanian organik.

Kecamatan Sambutan merupakan salah satu kecamatan yang ada di wilayah Kota Samarinda dengan luas wilayah 71.800 ha dan jumlah penduduk 36.841 jiwa terbagi menjadi 5 kelurahan (Badan Pusat Statistik, 2015). Kelurahan Makroman merupakan salah satu kelurahan di Kecamatan Sambutan, Kota Samarinda, Provinsi Kalimantan Timur. Kelurahan ini memiliki jumlah penduduk 8.343 jiwa atau $2.553 \mathrm{KK}$. Rata-rata petani di Kelurahan Makroman berusahatani padi sawah dan hortikultura dengan luas tanam padi sawah sebesar 169,5 ha, luas panen 169,5 ha, jumlah produksi 1007,5 Mg, dan produktivitas sebanyak $5,94 \mathrm{Mg} \mathrm{ha}^{-1}$. Jumlah seluruh kelompok tani di Kelurahan 
Makroman sebanyak 17 kelompok, sedangkan kelompok tani yang berusahatani padi sawah sebanyak 6 kelompok (Programa Penyuluhan Pertanian Kelurahan Makroman, 2015).

Kelurahan Makroman adalah kelurahan yang merupakan salah satu sentra produksi padi sawah yang ada di Kecamatan Sambutan dan di kelurahan ini telah beberapa kali dilakukan penyuluhan dan pelatihan tentang pertanian organik. Tingkat pengetahuan dari petani dipengaruhi oleh beberapa faktor sosial ekonomi, seperti pendidikan, media masa, lingkungan dan lain sebagainya. Kendala-kendala yang dihadapi oleh petani yang ada di Kelurahan Makroman yaitu masih kurangnya pengetahuan tentang budidaya pertanian organik secara keseluruhan.

Sehingga sangat diperlukan pengetahuan yang lebih luas dari petani terhadap budidaya pertanian organik agar pertanian organik dapat dikembangkan secara optimal. Berdasarkan uraian di atas penulis tertarik untuk mengkaji dan mengadakan penelitian dengan judul "Analisis Hubungan Faktor Sosial Ekonomi Petani Terhadap Pengetahuan Budidaya Pertanian Organik Padi Sawah (Oryza sativa L.) di Kelurahan Makroman Kecamatan Sambutan".

\section{Metode Penelitian}

\section{Metode Pengambilan Sampel}

Pemilihan sampel wilayah kelurahan dilakukan secara sengaja (purposive sampling) dan metode pengambilan sampel yang digunakan secara proporsional (Proportionate Random Sampling), yaitu pengambilan sampel tanpa memperhatikan strata yang terdapat pada suatu populasi (Sugiyono, 2010). Responden yang dijadikan sampel sebanyak 38 responden.

\section{Metode Analisis Data}

a. Faktor Sosial Ekonomi yang Mempengaruhi Pengetahuan Petani

Metode penelitian yang digunakan dalam penelitian ini adalah metode penelitian yang menggunakan pendekatan kualitatif, karena penelitian ini bersifat deskriptif.

b. Tingkat Pengetahuan Petani Terhadap Budidaya Pertanian Organik Padi Sawah

Pengujian untuk mengetahui tingkat pengetahuan petani terhadap budidaya pertanian organik diukur dengan lima indikator. Pengukuran lima indikator tersebut menggunakan metode pengukuran Likert. Metode ini menggunakan metode skoring, maksudnya bahwa setiap jawaban yang tersedia diberikan skor yang berbeda. Pilihan jawaban yang paling tinggi yaitu jawaban A diberikan skor tertinggi yaitu skor 3 , sedangkan jawaban $\mathrm{B}$ dan $\mathrm{C}$ masing-masing diberikan skor 2 dan 1

c. Hubungan Antara Faktor Sosial Ekonomi Petani dengan Budidaya Pertanian Organik Padi Sawah 
Menurut Sugiyono (2010) untuk mengetahui hubungan faktor sosial ekonomi petani terhadap budidaya pertanian organik padi sawah, digunakan metode analisis korelasi rank spearman (rs). Setelah hasil dari analisis korelasi rank spearman (rs) didapat, dilanjutkan dengan menguji tingkat signifikan dari hubungan faktor sosial ekonomi petani terhadap budidaya pertanian organik padi sawah dengan menggunakan rumus uji t.

\section{Hasil dan Pembahasan}

\section{Peran Faktor Sosial Ekonomi Petani Terhadap Budidaya Pertanian Organik Padi}

\section{Sawah}

Tabel 1. Peran Faktor Sosial Ekonomi Petani Terhadap Budidaya Pertanian Organik Padi Sawah

\begin{tabular}{rlrrr}
\hline No. & Faktor Sosial Ekonomi Petani & $\begin{array}{r}\text { Total } \\
\text { Skor }\end{array}$ & Rata-rata & Kategori \\
\hline 1 & Pendidikan & 592 & 15,57 & Kurang Berperan \\
2 & Media Masa/Sumber Informasi & 423 & 11,13 & Kurang Berperan \\
3 & Sosial Budaya dan Ekonomi & 303 & 7,97 & Berperan \\
4 & Lingkungan & 407 & 10,71 & Kurang Berperan \\
5 & Pengalaman & 414 & 10,89 & Kurang Berperan \\
\hline & Jumlah & 2139 & 56,28 & Kurang Berperan \\
\hline & Sumber: Data primer (diolah), 2017 & & \\
& Berdasarkan Tabel 1, hasil penelitian secara keseluruhan indikator faktor sosial
\end{tabular}

ekonomi petani terhadap budidaya pertanian organik padi sawah menunjukkan bahwa pengaruh faktor pendidikan masuk kedalam kategori kurang berperan dengan rata-rata skor sebesar 15,57, faktor media masa/sumber informasi masuk kedalam kategori kurang berperan dengan rata-rata skor sebesar 11,13, faktor sosial budaya dan ekonomi masuk kedalam kategori berperan dengan rata-rata skor sebesar 7,97, faktor lingkungan masuk kedalam kategori kurang berperan dengan rata-rata skor sebesar 10,71 dan faktor pengalaman masuk kedalam kategori kurang berperan dengan rata-rata skor sebesar 10,89. Hasil penelitian pada Tabel 1 secara keseluruhan indikator faktor sosial ekonomi petani terhadap budidaya pertanian organik padi sawah rata-rata berkategori kurang berperan dengan skor rata-rata keseluruhan indikator sosial ekonomi petani sebesar 56,28. Hal ini menunjukkan bahwa peran faktor sosial ekonomi petani rata-rata masih kurang berperan terhadap budidaya pertanian organik padi sawah di lokasi penelitian.

Faktor sosial seperti pendidikan formal yang pernah ditempuh petani belum memberikan pengetahuan tentang budidaya pertanian organik, faktor media masa masih kurang berperan karena kurangnya niat petani untuk mencari informasi terkait budidaya pertanian organik, lingkungan di sekitar petani juga menjadi faktor yang kurang berperan karena masih kurangnya informasi yang petani dapatkan di sekitar lingkungan mereka, dan faktor pengalaman petani masih kurang berperan karena masih rendahnya niat petani dalam mencoba menerapkan budidaya pertanian organik. 
Menurut Kanro, dkk (2002) tingkat pendidikan menggambarkan tingkat pengetahuan, wawasan, dan pandangan seseorang yang dalam bidang pertanian diartikan sebagai cara seseorang merespon suatu teknologi. Dengan pendidikan yang memadai transfer teknologi mudah terlaksana sehingga dapat memacu pengembangan teknologi di tingkat petani.

\section{Tingkat Pengetahuan Budidaya Pertanian Organik}

Tabel 2. Tingkat Pengetahuan Budidaya Pertanian Organik Padi Sawah

\begin{tabular}{ccccc}
\hline No. & $\begin{array}{c}\text { Pengetahuan Budidaya Pertanian } \\
\text { Organik }\end{array}$ & Total Skor & Rata - rata & Kategori \\
\hline 1 & Lahan & 590 & 15,52 & Tinggi \\
2 & Benih dan Bibit & 630 & 16,57 & Tinggi \\
3 & Pupuk & 447 & 11,76 & Tinggi \\
4 & PHPT & 393 & 10,34 & Sedang \\
5 & Irigasi & 224 & 5,89 & Sedang \\
\hline & Jumlah & 2.284 & 60,10 & Tinggi \\
\hline
\end{tabular}

Sumber: Data primer (diolah), 2017

Berdasarkan Tabel 2, hasil penelitian secara keseluruhan indikator tingkat pengetahuan petani terhadap budidaya pertanian organik padi sawah menunjukkan bahwa indikator lahan masuk kedalam kategori tinggi dengan rata-rata skor sebesar 15,52 , indikator benih dan bibit masuk kedalam kategori tinggi dengan rata-rata skor sebesar 16,57, indikator pupuk masuk kedalam kategori tinggi dengan rata-rata skor sebesar 11,76, indikator PHPT masuk kedalam kategori sedang dengan rata-rata skor sebesar 10,34 dan indikator irigasi masuk kedalam kategori sedang dengan rata-rata skor sebesar 5,89. Hasil penelitian pada Tabel 2 secara keseluruhan indikator tingkat pengetahuan petani terhadap budidaya pertanian organik padi sawah rata-rata berkategori tinggi dengan skor rata-rata keseluruhan indikator tingkat pengetahuan petani sebesar 60,10. Hal ini menunjukkan bahwa secara garis besar tingkat pengetahuan budidaya pertanian organik yang dilaksanakan di lokasi penelitian rata-rata termasuk kategori tinggi.

Pengetahuan petani tentang pengolahan lahan yang baik dan benar untuk budidaya pertanian organik sudah termasuk tinggi, petani mengetahui cara pengolahan lahan dan penggunaan bahan-bahan organik untuk meningkatkan kesuburan lahan, penggunaan benih dan bibit yang baik dan sehat juga sudah diketahui oleh petani dengan memperhatikan asal usul benih dan pemilihan bibit yang sehat sebelum ditanam. Pengetahuan petani tentang pupuk organik juga termasuk tinggi karena petani sudah mengetahui bahan-bahan organik dan cara pembuatan pupuk organik tersebut.

Tingkat pengetahuan petani masih tergolong sedang pada indikator pengendalian hama dan penyakit tanaman karena masih kurangnya pengetahuan petani tentang bahan-bahan pestisida organik serta cara pembuatan pestisida tersebut, serta 
ISSN 2354-7251 (print)

masih kurangnya pengetahuan petani pada indikator irigasi dikarenakan petani masih belum benar-benar mengetahui tentang irigasi yang baik dan mendukung untuk budidaya pertanian organik. Menurut Kishore, dkk dalam Yuantari ( 2013) bahwa pengetahuan petani kurang dalam memperhatikan penggunaan pestisida karena masih banyak petani yang buta huruf.

\section{Hubungan Faktor Sosial Ekonomi Petani Terhadap Budidaya Pertanian Organik Padi Sawah}

Faktor sosial ekonomi petani terhadap budidaya pertanian organik padi sawah di Kelurahan Makroman memiliki hubungan, hal ini berdasarkan hasil perhitungan rank sperman (rs) yang bernilai 0,892 lebih besar dari rs tabel yang bernilai 0,271 (rs hitung $>$ rs tabel). Hubungan faktor sosial ekonomi pertanian organik padi sawah di Kelurahan Makroman termasuk kategori signifikan. Dikarenakan t hitung yang bernilai 11,819 lebih besar dari t tabel yang bernilai 1.686 ( $\mathrm{t}$ hitung > t tabel).

Berdasarkan hasil yang didapatkan dari penelitian hubungan faktor sosial ekonomi dengan tingkat pengetahuan petani terhadap budidaya pertanian organik padi sawah di Kelurahan Makroman memiliki hubungan yang signifikan. Hal ini dikarenakan, walaupun faktor sosial ekonomi petani terhadap pengetahuan pertanian organik padi sawah rata-rata masih tergolong berkategori kurang berperan tetapi terdapat beberapa indikator faktor sosial ekonomi yang mempengaruhi pengetahuan petani seperti indikator sosial budaya dan ekonomi. Hubungan yang signifikan ini terbukti dengan rata-rata tergolong tingginya tingkat pengetahuan petani terhadap pengetahuan budidaya pertanian organik padi sawah di Kelurahan Makroman Kecamatan Sambutan. Hal ini dikarenakan peranan faktor sosial ekonomi dalam kehidupan petani yang ditunjang dengan adanya penyampaian informasi melalui penyuluhan dan pelatihan pertanian organik di Kelurahan Makroman Kecamatan Sambutan.

Berdasarkan hasil penelitian, faktor sosial ekonomi petani yang paling dominan terhadap pengetahuan budidaya pertanian organik padi sawah di Kelurahan Makroman Kecamatan Sambutan terdapat pada indikator sosial budaya dan ekonomi, dimana pada indikator tersebut petani memiliki pengetahuan tentang adanya kebiasaan dan tradisi tentang budidaya pertanian yang sehat tanpa bahan kimia, serta petani sudah mengetahui adanya perbedaan harga antara produk beras organik dan non organik. Sedangkan indikator yang kurang dominan ialah indikator pendidikan karena pada indikator tersebut masih kurangnya informasi tentang budidaya pertanian organik yang didapat petani pada saat mejalani pendidikan formal dan masih kurangnya partisipasi petani mengikuti pendidikan non formal seperti penyuluhan dan pelatihan budidaya pertanian organik. 
Berdasarkan hasil penelitian, pengetahuan budidaya pertanian organik padi sawah di Kelurahan Makroman Kecamatan Sambutan yang paling dominan terdapat pada indikator benih dan bibit, dimana pada indikator tersebut petani sudah mengetahui penggunaan benih yang unggul dan yang sesuai dengan lahan sawah milik petani serta pemilihan bibit yang sehat dan siap untuk ditanam. Sedangkan indikator yang kurang dominan ialah indikator irigasi, dimana pada indikator tersebut petani masih belum mengerti bagaimana irigasi yang sesuai untuk budidaya pertanian organik seperti sumber air irigasi dan penggunaan irigasi terpisah atau tertutup.

Menurut Utami (2013) dalam penelitiannya menyatakan tidak terdapat hubungan antara faktor sosial ekonomi petani konvensional dengan respon petani pada pertanian organik. Adanya beberapa ketidakberhubungan antara karakteristik petani dengan respon petani pada pertanian tersebut karena individu dengan berbagai karakteristik dapat memiliki respon yang rendah atau tinggi pada pertanian organik.

\section{Kesimpulan}

Berdasarkan hasil penelitian mengenai tingkat pengetahuan petani terhadap pengetahuan budidaya pertanian organik padi sawah di Kelurahan Makroman Kecamatan Sambutan, dapat ditarik kesimpulan sebagai berikut:

a. Faktor sosial ekonomi petani terhadap budidaya pertanian organik padi sawah di Kelurahan Makroman Kecamatan Sambutan rata-rata termasuk dalam kategori kurang berperan.

b. Tingkat pengetahuan budidaya pertanian organik padi sawah di Kelurahan Makroman Kecamatan Sambutan rata-rata termasuk dalam kategori tinggi.

c. Hubungan faktor sosial ekonomi petani terhadap budidaya pertanian organik padi sawah di Kelurahan Makroman Kecamatan Sambutan memiliki hubungan yang signifikan dikarenakan $r s$ hitung $>r$ tabel $(0,892>0,271)$ dan $t$ hitung $>t$ tabel $(11,819>1,686)$.

\section{Daftar Pustaka}

Amaliah. (2014). Permasalahan Dalam Pengembangan Pertanian Organik. http:// amaliah84.files.wordpress.com/2014/11/ permasalahan-dalam-pengembanganpertanian-organik.pdf. Akses pada tanggal 26 Februari 2017.

Badan Pusat Statistik. (2015). Kecamatan Sambutan. Kota Samarinda.

Balai Penyuluhan Pertanian Perikanan dan Kehutanan Mitra Tani Sambutan. (2015). Program Penyuluhan Pertanian Kelurahan Makroman Kecamatan Sambutan. Samarinda.

Kanro, M. Z. (2002). Pengelolaan Sistem Usahatani Tanaman Pangan dan Upaya Perbaikannya di Papua. Jurnal Litbang Pertanian. 21(4). Pada http;//pustaka.litbang.deptan.go.id/publikasi_content.php.

Kelurahan Makroman. (2016). Data Monografi Kelurahan Makroman. Samarinda. 
Sugiyono. (2010). Statistik Nonparemetris. Alfabeta. Bandung.

Susanti, L.W. (2008). Faktor-Faktor Yang Mempengaruhi Pengambilan Keputusan Petani Dalam Penerapan Pertanian Padi Organik Di Desa Sukorejo Kecamatan Sambirejo Kabupaten Sragen. Skripsi. Fakultas Pertanian Universitas Sebelas Maret. Surakarta.

Utami, F. E. ()2013. Pengembangan Pertanian Organik Di Kelompok Tani Madya, Desa Kebonagung, Kabupaten Bantul, Daerah Istimewa Yogyakarta. Skripsi. Institute Pertanian Bogor. Bogor.

Yuantari, MG.C., Budi, W., Henna, R.S. (2013). Tingkat Pengetahuan Petani dalam Menggunakan Pestisida (Studi Kasus di Desa Curut Kecamatan Penawangan Kabupaten Grobogan). Dalam Seminar nasional Pengelolaan Sumberdaya Alam dan Lingkungan "Optimasi Pengelolaan Sumberdaya Alam dan Lingkungan dalam Mewujudkan Pembangunan Berkelanjutan", 27 Agustus 2013 